\section{CS58: new high yielding, salt and alkaline tolerant cultivar of Indian mustard}

\section{Jogendra Singh ${ }^{1}$, Parbodh Chander Sharma ${ }^{1^{*}}$, Vijayata Singh ${ }^{1}$, Dinesh Kumar Sharma ${ }^{1}$, Sajjan Kumar Sharma ${ }^{2}$, Yash Pal Singh ${ }^{4}$ and Raja Bahadur Singh ${ }^{3}$}

\begin{abstract}
CS58 is a newly developed, salt-tolerant, high-yielding Indian mustard variety from ICAR-CSSRI, Karnal, India, to harness the yield potential of saltaffected soils of India. It produced 24-25\% higher seed yield than the national check varieties CS54 and Kranti and was well received and adopted by farmers in salt-affected areas of the country during on-farm demonstrations.
\end{abstract}

Keywords: Brassica juncea, salt and alkaline tolerance, high seed and oil yield.

\section{INTRODUCTION}

Salinity and sodicity stresses affect an area of 932.2 million hectares in the world (Szabolcs 1989); an area of nearly 6.73 million hectares is affected by these stresses in India (NRSA 1996, Singh et al. 2014). Indian mustard (Brassica juncea $\mathrm{L}$. Czern and Coss) is an important oil-seed crop in the world and is grown in more than 50 countries across the globe. This crop is often subject to saline stress, as it is grown extensively in arid and semi-arid regions of the world. Soil and water salinity stresses contribute to greater yield losses (both seed and oil yield), and this low economic yield is related to susceptibility of the crop (Singh and Sharma 2016). There is a considerable need to improve crop plants for salinity tolerance. Moreover, Indian mustard has received increasing attention due to its potential to phytoremediate metal-polluted saline soils (Novo et al. 2013 , Novo et al. 2014). Hence, it is necessary to develop salt-tolerant genotypes in Indian mustard.

Selection of elite germplasm in intermediate climatic growing conditions allows selection of a suitable germplasm across the diverse range of climatic conditions evaluated (da Silva et al. 2019). One approach is characterization of the available germplasm in salt affected environment, which provide an initial germplasm base for breeding salt-tolerant crops.

High-yielding, salt-tolerant Indian mustard varieties play an important role in harnessing the yield potential of salt-affected soils (Singh and Sharma 2016). ICAR-Central Soil Salinity Research Institute (ICAR-CSSRI) has developed three salt-tolerant varieties of Indian mustard, viz., CS52, CS54, and CS56, through traditional plant breeding, which have had a favorable impact on salt-affected areas of India. However, integration of farmer-participatory variety selection in traditional plant breeding strengthens and expedites the adoption of varieties by farmers, who are the end users of varietal technology. In this quest, a new
Crop Breeding and Applied Biotechnology 19(4), 451-455, 2019 Brazilian Society of Plant Breeding. Printed in Brazil http://dx.doi.org/10.1590/198470332019v19n4c63

\footnotetext{
*Corresponding author: E-mail: pcsharma.knl@gmail.com (i) ORCID: 0000-0002-5783-7480
}

Received: 08 July 2017 Accepted: 05 September 2018

${ }^{1}$ ICAR-Central Soil Salinity Research Institute, Karnal-132001, Haryana, India

2 Raja Balwant Singh College, Bichpuri, Agra238105, Uttar Pradesh, India ${ }^{3}$ ICAR - Central Soil Salinity Research Institute, Regional Research Station, Lucknow226002, Uttar Pradesh, India 
variety CS58 not only performed better in the All India Salinity Alkalinity Tolerant Variety Trials (AISATVT) in different salinity and alkalinity stress locations, including the states of Haryana, Punjab, and Uttar Pradesh, but was also well received and adopted by farmers in salt-affected areas of the country.

Using these approaches, salt-tolerant varieties and pre-breeding materials of Indian mustard were screened and evaluated under varied saline and alkaline environments in India from 2012-13 to 2015-16 by the multi-disciplinary team of scientists of ICAR-CSSRI.

\section{PEDIGREE AND BREEDING METHOD}

The Indian mustard variety CS58 was developed by crossing two genotypes, CS52 and CS609-B10. The CS52 is a highly salt-tolerant variety, and CS609-B10 is a high-yielding (seed and oil) genotype. The $50 \mathrm{~F}_{1}$ crosses were space planted and harvested in bulk. The $F_{2}$ to $F_{6}$ generations were planted at the commercial seed rate and spacing and harvested in bulk. The population size in each of these generations was 30 thousand plants. About 30 thousand plants were space planted in the $\mathrm{F}_{7}$ generation, and from these plants, only 5000 plants with higher primary and secondary branches, high main shoot length, and higher number of siliques on the main shoot under salinity $\left(12.0 \mathrm{~d} \mathrm{Sm}^{-1}\right)$ and alkalinity (pH 9.4) conditions were selected, and their seeds were harvested separately. Individual plant progenies were grown in multi-row plots. Weak and inferior progenies were rejected, and only 300 individual homozygous plant progenies with desirable traits were selected and harvested in bulk. A preliminary yield trial was conducted at the ICAR-CSSRI experimental farms for two years, along with the national check varieties CS54 and Kranti, for agronomic traits; and Rohini, YSB9, PHR2, EC399301, EC399299, EC399000, DLSC-1, and Varuna were used as checks for resistance/tolerance to disease and mustard aphid infestation. Replicated yield trials were conducted for three years at 5 locations per year under saline and alkaline conditions in salt-affected soils of the states of Haryana, Punjab, Rajasthan, and Uttar Pradesh

Table 1. Seed and oil yield ( $\left.\mathrm{kg} \mathrm{ha}^{-1}\right)$ of cultivars under saline (ECe $12 \mathrm{~d} \mathrm{Sm}^{-1}$ ) and alkaline ( $\left.\mathrm{pH} 9.4\right)$ conditions in an all India coordinated research project on rapeseed-mustard (AICRPRM)

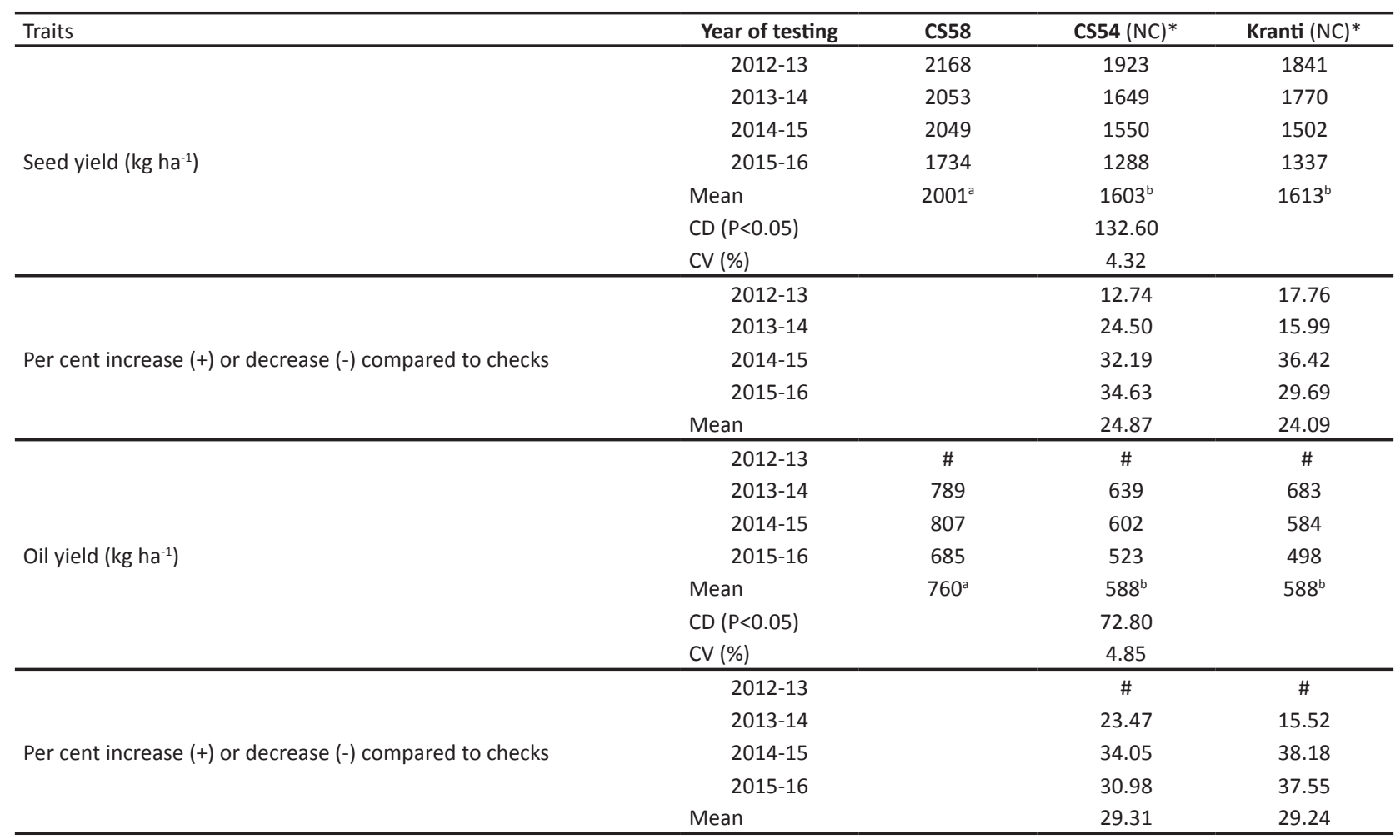

*NC = National Check; \# in the year 2012-13, data on oil yield were not reported, CD = critical difference, CV = coefficient of variation. Means with the same letter in the row did not have a statistically significant difference at $P<0.05$ by Duncan's Multiple Range Test. 
using the standard national check varieties CS54, RH749, RH406, NRCHB101, DRMRIJ31, and Kranti under an all India coordinated research project on rapeseed-mustard (AICRPRM). CS58 was more than 10\% superior to the standard checks in terms of seed and oil yield and disease and pest tolerance under saline and alkaline conditions. Thus, it was released as a new variety.

\section{TRAIT PERFORMANCE}

On the basis of four-year (2012-13 to 2015-16) trials conducted for saline and alkaline conditions in AICRPRM, CS58 provided a mean seed yield of $2001 \mathrm{~kg} \mathrm{ha}^{-1}$ under saline and alkaline conditions, which was $24 \%$ and $25 \%$ higher than the yields of two national check varieties, i.e., CS54 (1603 kg ha-1) and Kranti (1613 kg ha-1), respectively. It also provided $29 \%$ higher oil yield (760 $\left.\mathrm{kg} \mathrm{ha}^{-1}\right)$ than CS54 and Kranti (588 $\left.\mathrm{kg} \mathrm{ha}^{-1}\right)$ (Table 1). This variety matures, on average, in 135 days, and takes 60 days to flower. It attains a height of approximately $180 \mathrm{~cm}$, main shoot length of $85 \mathrm{~cm}$, and 1000 seed weight of $5 \mathrm{~g}$ (Table 2).

Table 2. Ancillary data of cultivars under saline (ECe $\left.12 \mathrm{~d} \mathrm{Sm}^{-1}\right)$ and alkaline (pH 9.4) conditions in AICRPRM

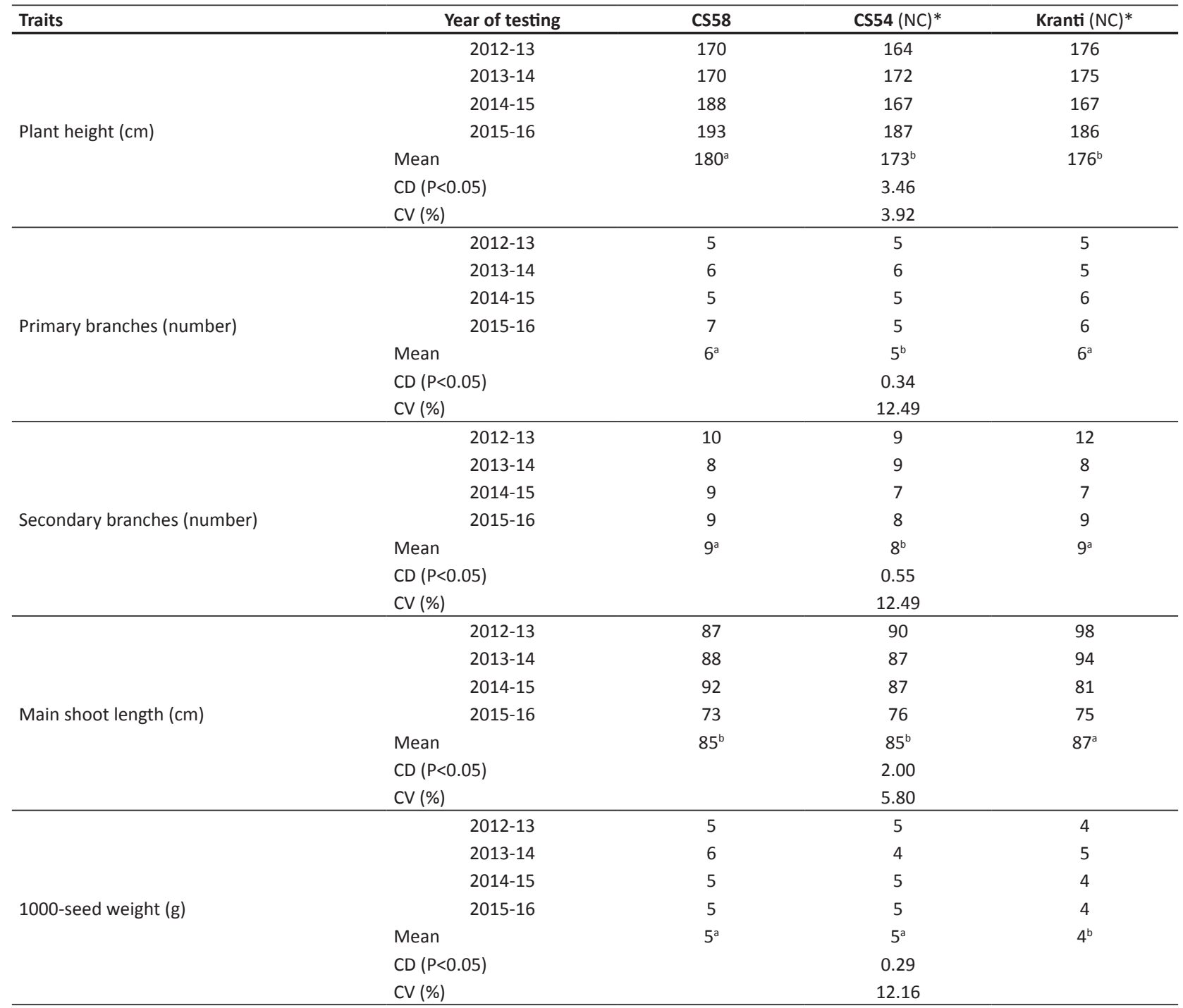

*NC $=$ National Check, $C D=$ critical difference, $C V=$ coefficient of variation. Means with the same letter in the row do not have a statistically significant difference at $\mathrm{P}<$ 0.05 by Duncan's Multiple Range Test. 
CS58 also showed higher resistance to Alternaria blight under natural conditions than the check Rohini and the salttolerant variety CS54. The severity of Alternaria blight in pods was similar to the checks. Furthermore, it also showed much lower incidence of white rust, powdery mildew, downy mildew, and Sclerotinia rot compared to the check Rohini.

Table 3. Score for reaction to major diseases (100 days after sowing under natural conditions) of cultivars under saline (ECe $12 \mathrm{~d}^{\mathrm{S}} \mathrm{m}^{-1}$ ) and alkaline ( $\mathrm{pH}$ 9.4) conditions in AICRPRM

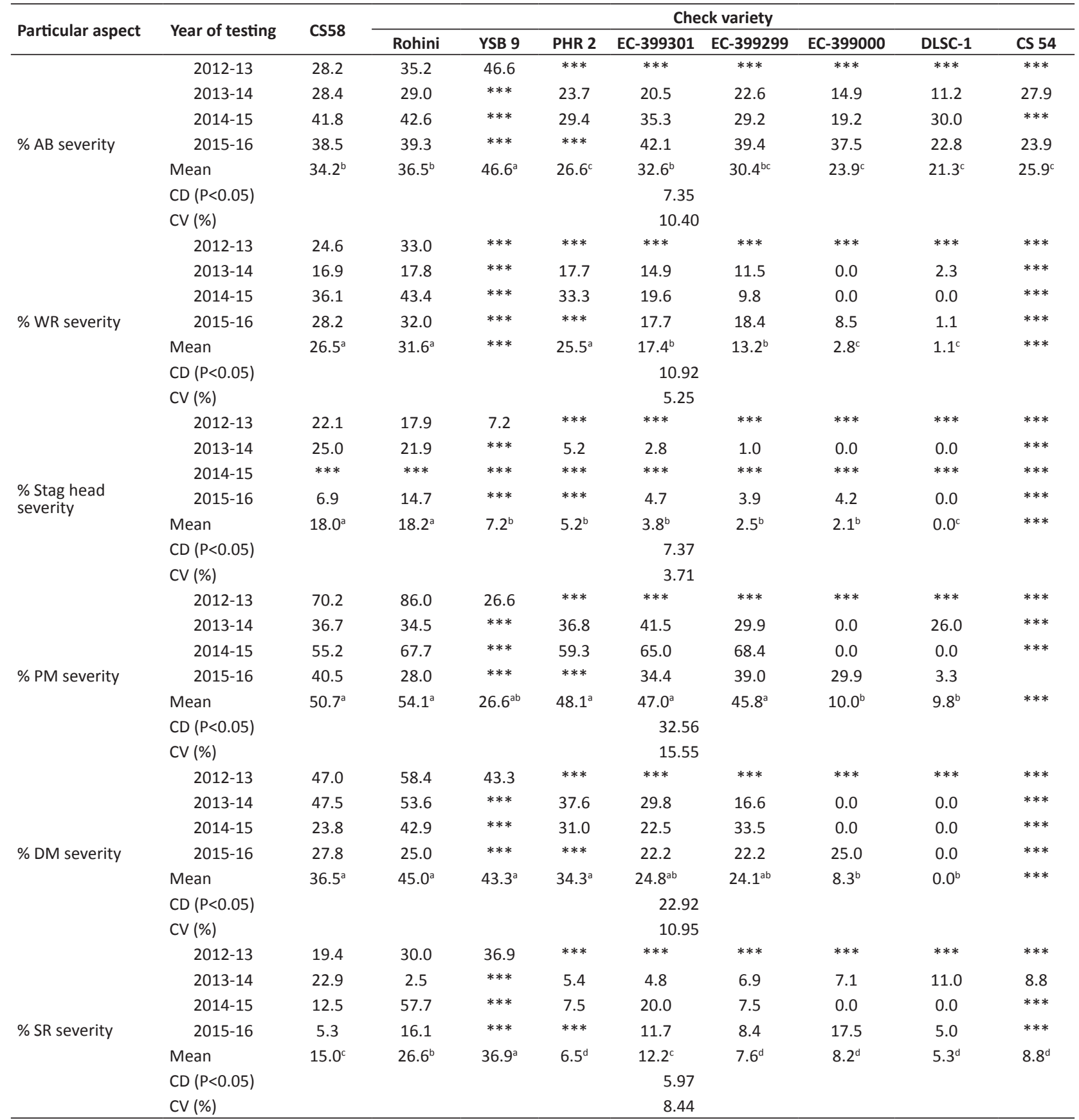

$\mathrm{AB}=$ Alternaria blight, $\mathrm{WR}=$ White rust, $\mathrm{PM}=$ Powdery mildew, $\mathrm{DM}=$ Downy mildew, $\mathrm{SR}=$ Sclerotinia rot, $\mathrm{CD}=\mathrm{critical}$ difference, $\mathrm{CV}=\mathrm{coefficient}$ of variation. $* * *$ Not a check variety for the specific disease in the specific trial (initial or advance varietal trial) of this year. Means with the same letter in the row do not have a statistically significant difference at $\mathrm{P}<0.05$ by Duncan's Multiple Range Test. 
CS58: new high yielding, salt and alkaline tolerant cultivar of Indian mustard

Table 4. Score for reaction to mustard aphid of cultivars under saline (ECe $12 \mathrm{~d} \mathrm{Sm}^{-1}$ ) and alkaline (pH 9.4) conditions in AICRPRM

\begin{tabular}{|c|c|c|c|c|c|c|}
\hline \multirow{2}{*}{ Particular aspect } & \multirow{2}{*}{ Year of testing } & \multirow{2}{*}{ CS58 } & \multicolumn{4}{|c|}{ Check variety } \\
\hline & & & CS 54 & Kranti & Rohini & Varuna \\
\hline \multirow{5}{*}{ Average aphid infestation index (AAll) } & $2012-13$ & 1.3 & 1.4 & 1.3 & 1.5 & 1.5 \\
\hline & 2013-14 & 1.1 & 1.3 & 1.5 & 1.2 & 1.2 \\
\hline & 2014-15 & 1.5 & 1.9 & 1.8 & 2 & 1.7 \\
\hline & $2015-16$ & 1.9 & $* *$ & $* *$ & 2.3 & 2.6 \\
\hline & Mean & $1.5^{\mathrm{b}}$ & $1.5^{b}$ & $1.5^{\mathrm{b}}$ & $1.8^{\mathrm{a}}$ & $1.8^{\mathrm{a}}$ \\
\hline
\end{tabular}

** Not a check variety for mustard aphid in this year. $C D=$ critical difference, $C V=$ coefficient of variation. Means with the same letter in the row do not have a statistically significant difference at $\mathrm{P}<0.05$ by Duncan's Multiple Range Test.

Similar performance was recorded under artificial conditions (Table 3). Against mustard aphid, data from 24 trails showed a lower average aphid infestation index (AAll) compared to the checks CS54, Kranti, Rohini, and Varuna (Table 4).

CS58 responded favorably to additional application of fertilizer (NPK). Further recommended dose of fertilizer (80:40:40; N:P:K, kg ha-1, respectively) was found suitable for this genotype.

Considering its higher seed and oil yields and disease resistance under saline (6.0-12.0 d Sm$\left.)^{-1}\right)$ and alkaline $(\mathrm{pH} 9.0-$ 9.4) conditions, CS58 was released for salt-affected soils of the country.

\section{SEED PRODUCTION}

Genotype CS58 was released and notified by the central sub-committee on "crop standards, notification, and release of varieties" (see the notification in the official gazette for this variety: number S.O. 1007 (E), dated 30 March 2017), under the Department of Agriculture and Cooperation, Ministry of Agriculture and Farmers Welfare, Government of India. ICAR-CSSRI is the developer and maintainer of this cultivar and produces its genetic seeds.

\section{REFERENCES}

da Silva PHM, Marco M, Alvares CA, Lee D, de Moraes MLT and de Paula RC (2019) Selection of Eucalyptus grandis families across contrasting environmental conditions. Crop Breeding and Applied Biotechnology 19: $47-54$

Novo LAB, Covelo EF and González L (2014) Effect of salinity on zinc uptake by Brassica juncea. International Journal of Phytoremediation 16: 704-718.

Novo LAB, Covelo EF, Manousaki E, Kalogerakis N and González L (2013) The effect of cadmium and salinity on germination and early growth of Brassica juncea (L.) var. juncea. Fresenius Environmental Bulletin 22: 3709-3717.

NRSA - National Remote Sensing Agency (1996) Mapping salt-affected soils of India on 1:250000. Available at: <http://bhuvan-noeda.nrsc. gov.in/theme>. Accessed on July 8, 2017.

Silva PHM, Marco M, Alvares CA, Lee D, Moraes MLT and Paula RC (2019) Selection of Eucalyptus grandis families across contrasting environmental conditions. Crop Breeding and Applied Biotechnology 19: 47-54.

Singh J and Sharma PC (2016) Comparative effects of soil and water salinity on oil quality parameters of Brassica juncea. Journal of Oilseed Brassica 7: 29-37.

Singh J, Sharma PC, Sharma SK and Rai M (2014) Assessing the effect of salinity on the oil quality parameters of Indian mustard (Brassica juncea L. Czern and Coss) using fourier transform near-infrared reflectance (FT-NIR) spectroscopy. Grasas Y Aceites 65: e009.

Szabolcs I (1989) Salt-affected soils. CRC Press, Boca Raton, 274p.

(cc) EY This is an Open Access article distributed under the terms of the Creative Commons Attribution License, which permits unrestricted use, distribution, and reproduction in any medium, provided the original work is properly cited. 